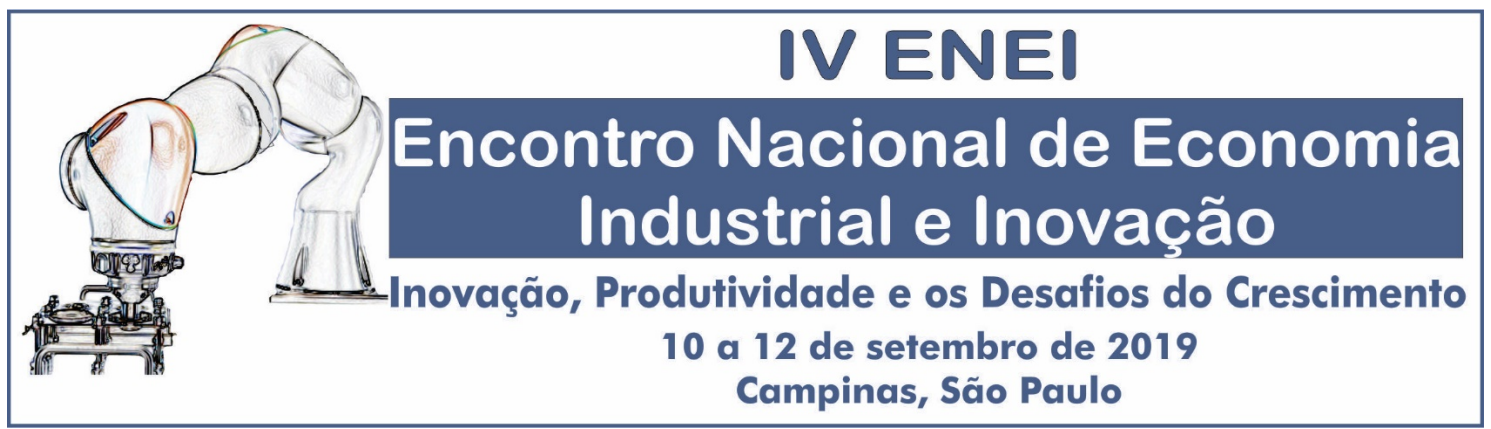

\title{
HETEROGENEIDADE ESTRUTURAL NA INDÚSTRIA BRASILEIRA: uma análise segundo porte, setor e tempo de existência das empresas ${ }^{1}$
}

\author{
Marisa dos Reis A. Botelho* \\ Michelle de Castro Carrijo \\ Juliene Barbosa Ferreira ${ }^{\wedge}$ \\ Graciele de Fátima Sousa* \\ Ariana Cericatto da Silva
}

RESUMO - A indústria brasileira caracteriza-se por elevado grau de heterogeneidade, segundo diversos estudos recentes. O objetivo deste artigo é contribuir para essa discussão a partir de um conjunto de dados que evidenciam a heterogeneidade relativa ao porte, setor e ao tempo de existência das empresas na indústria de transformação brasileira para o período de 2007 a 2016. Foi realizada uma análise descritiva dos dados, que foram obtidos da Pesquisa Industrial Anual Empresa (PIA/Empresa) e do Cadastro Central de Empresas (CEMPRE), ambos do IBGE. Os resultados encontrados, a partir da análise do indicador de produtividade do trabalho, considerando o porte da firma, o tempo de existência e o setor de atividade em que a empresa atua, permitem mostrar que a heterogeneidade extrapola a conhecida relação com o porte. Verificou-se que a heterogeneidade é bastante significativa também intraporte, segundo tempo de existência e setor de atividade. Ao abordar a questão de porte e longevidade, entende-se que este trabalho contribui para a discussão da situação da indústria frente ao processo de desindustrialização em curso na economia brasileira.

Palavras-Chave- Indústria brasileira; Heterogeneidade produtiva; Porte das empresas

ABSTRACT- Brazilian industry is characterized by a high degree of heterogeneity, according to several recent studies. The main purpose of this paper is to contribute to this discussion using a set of data that

\footnotetext{
${ }^{1}$ As autoras agradecem o apoio financeiro da Fundação de Apoio à Pesquisa de Minas Gerais (Fapemig) à elaboração deste trabalho, por meio do projeto Demanda Universal (APQ 02761-15).

* Instituto de Economia e Relações Internacionais - IERI e Programa de Pós-Graduação em Economia - PPGE da Universidade Federal de Uberlândia - UFU. Bolsista Produtividade do CNPQ. E-mail: botelhomr@ufu.br

- Professora da Faculdade de Gestão e Negócios da Universidade Federal de Uberlândia - UFU. E-mail: michellecarrijo@ufu.br

^ Professora da Universidade Federal do Triangulo Mineiro - UFMT. Email: juliene.ferreira@ufu.br

* Economista do Centro de Estudos, Pesquisas e Projeto Econômico-Sociais - CEPES do Instituto de Economia e Relações Internacionais - IERI da Universidade Federal de Uberlândia - UFU. E-mail: graciele.sousa@yahoo.com.br

- Doutoranda no Programa de Pós-Graduação em Economia - PPGE da Universidade Federal de Uberlândia -UFU. Email: ariana_cericatto@hotmail.com
} 
show the heterogeneity relative to the size, sector, and time of existence of the companies in the Brazilian manufacturing industry for the period from 2007 to 2016. A descriptive analysis of the data was performed, which were obtained from the Pesquisa Industrial Anual Empresa (PIA/Empresa) and of the Cadastro Central de Empresas (CEMPRE), both of IBGE. The results obtained, based on the analysis of the labor productivity indicator, considering the size of the firm, the time of existence and the sector, show that the heterogeneity goes beyond the known relation with the size. It was verified that the heterogeneity is quite significant also within the size range, according to time of existence and sector of activity. In addressing the issue of size and longevity, it is understood that this work contributes to the discussion of the situation of the industry in the face of the ongoing process of de-industrialization in the Brazilian economy.

Key words - Brazilian industry; Productive heterogeneity; Firm size

Códigos JEL - L25; L60.

\section{Introdução}

O tema da heterogeneidade estrutural (HE) passa a fazer parte de forma mais intensa dos debates acadêmicos a partir dos anos de 1950, após o período pós-Segunda Guerra. Muitos autores, como Prebisch (1950), Lewis (1954) e Solow (1956), desenvolveram trabalhos seminais buscando compreender as diferenças estruturais dentro das economias. Na América Latina e Caribe, foi com a criação da Comissão Econômica para América Latina e Caribe (CEPAL) que essa discussão ganhou força. Baseada em uma perspectiva estruturalista, essa escola do pensamento defendia que essas economias absorveram o progresso tecnológico de forma assimétrica e heterogênea, o que teria elevado às diferenças de produtividade e, consequentemente, teria levado às profundas desigualdades na composição industrial.

Esse tema assume um grau maior de complexidade quando se trata das pequenas e médias empresas (PMEs) que, de modo geral, são categorizadas como empresas com baixa especialização, administração centralizada, simplicidade e informalidade do sistema de informações, atuação no mercado local, dificuldade de acesso às economias de escala. Essas características são tratadas pela literatura como barreiras/limitantes que esse segmento de empresas enfrenta perante às grandes empresas (MAZZALI; SOUZA, 2008). Entretanto, é importante destacar que essas características podem não ser a realidade de uma parte das PMEs, dado que algumas delas estão inseridas em setores mais dinâmicos e de alta intensidade tecnológica. Ou seja, nota-se uma grande heterogeneidade entre as empresas por porte e por setor.

Dessa forma, a diversidade estrutural impossibilita tratar as empresas de forma homogênea, nem no que se refere às condições que explicam sua sobrevivência e seu crescimento, nem no âmbito das medidas de políticas públicas, voltadas à sua promoção. A própria heterogeneidade conduz à dificuldade de se encontrar argumentos a favor de medidas indiscriminadas de apoio e promoção que se sustentem, sem maiores qualificações (SOUZA, 1995).

À luz dessas considerações, este trabalho busca contribuir para a discussão da HE da indústria brasileira ao sistematizar um amplo conjunto de dados inéditos, que evidenciam a manifestação da HE relativas ao porte e ao tempo de existência da empresa na indústria de transformação brasileira, para o período de 2007 a 2016. Os objetivos específicos são: (i) apresentar as diferenças de produtividade ao longo do tempo por porte e por idade; (ii) apresentar as diferenças setorial por porte e por idade em dois pontos do tempo, quais sejam, 2007 e 2016.

Para cumprir esses objetivos, foram levantados para análise, a partir de uma tabulação especial, dados secundários da Pesquisa Industrial Anual Empresa (PIA/Empresa) e do Cadastro Central de Empresas (CEMPRE), ambas desenvolvidas pelo Instituto Brasileiro de Geografia e Estatística (IBGE). A principal variável investigada foi a produtividade do trabalho, medida pela relação do Valor da Transformação Industrial (VTI) pelo Pessoal Ocupado (PO). 
Além dessa Introdução e das Considerações Finais, o trabalho foi estruturado em mais três seções. A seção 2 traz o referencial analítico, onde se resgata a discussão de heterogeneidade estrutural a partir de Pinto (1970), e se destacam os trabalhos que consideram as diferenças de produtividade segundo o porte. A seção 3 apresenta a metodologia utilizada para o desenvolvimento do trabalho, enquanto a seção 4 dedica-se à análise dos resultados encontrados.

\section{Referencial analítico}

A discussão sobre heterogeneidade estrutural na América Latina se originou, em especial, dos trabalhos iniciais de Raúl Prebisch, os quais buscavam compreender a forma particular com que as economias latino-americanas se desenvolviam, a partir do incremento tecnológico de forma desigual. $\mathrm{O}$ tema se difundiu em âmbito internacional no período pós-guerra, quando as economias envolvidas no conflito começaram seus processos de reconstrução, buscando reduzir o hiato econômico existente entre os países ricos e os pobres. No âmbito do mainstream economics, Lewis (1954) também apontava a dualidade estrutural, ou seja, identificava a existência de heterogeneidade nas estruturas produtivas, a qual estava alicerçada na presença conjunta de dois tipos de estruturas, uma moderna e outra atrasada. $\mathrm{Na}$ América Latina e Caribe, desde a criação da Comissão Econômica para América Latina e Caribe (CEPAL), esse tema mereceu forte atenção. Sua perspectiva crítica ao subdesenvolvimento, acabou por torná-la uma escola do pensamento, preocupada em compreender o modelo de mudanças estruturais ocorridas ao longo do tempo na América Latina e Caribe, uma vez que a modernização desses países ocorreu de forma heterogênea, reforçando, assim, as desigualdades regionais e intra-regionais.

A análise da HE aqui apresentada, parte do embasamento teórico proposto por Pinto (1970), cuja premissa é de que existem três estruturas principais que se manifestam de forma mais pungentes, sendo: i) uma estrutura 'primitiva', a qual apresenta níveis de produtividade do trabalho mais baixos, que se assemelham àqueles encontrados na economia no período colonial; ii) no outro extremo, apresenta uma estrutura 'moderna', que possui níveis de produtividade próximos à média das economias de países desenvolvidos e, por fim, iii) uma estrutura 'intermediária', que se caracteriza justamente por se encaixar entre as duas anteriores. Embora com mudanças ao longo do tempo, entende-se que essa tipologia continua representativa da economia dos países latino-americanos e, em particular, do Brasil.

A partir dessa perspectiva, define-se que a heterogeneidade estrutural ocorre quando se observa diferenças de produtividade entre as estruturas primitiva, moderna e intermediária, cuja descontinuidade estrutural é marcante entre (e dentre) os setores produtivos, de forma que não se observa uma tendência à homogeneização (ou seja, a camada moderna não consegue 'arrastar' a produtividade dos setores atrasados) e a representatividade do setor atrasado é particularmente notável, principalmente se comparado às economias desenvolvidas (CEPAL, 2010b; PINTO, 1970; PIRES 2016). Segundo Pinto (1970), a persistência de setores produtivos com diferentes níveis de produtividade tende a reproduzir a separação entre um setor dinâmico, estruturado ou formal, e um setor tradicional, não estruturado ou informal, que ficam excluídos de um cenário de desenvolvimento econômico e progresso social.

A perspectiva cepalina de análise da HE continua orientando trabalhos recentes desenvolvidos sobre esse tema, direta ou indiretamente. Araújo e Costa (2012) e Nogueira (2017), dentre outros, entendem que uma economia desenvolve e homogeneíza sua estrutura produtiva no longo prazo ao transferir mão de obra dos setores de baixa produtividade para os setores de alta produtividade. Nesse sentido, a produtividade do trabalho pode aumentar por duas razões, quais sejam, pelo deslocamento de fatores produtivos dos setores atrasados para os setores modernos da economia e pelo aumento intrínseco da produtividade de cada setor que é gerado pelas mudanças tecnológicas que ocorrem ao longo do desenvolvimento de cada país.

O desenvolvimento tecnológico insuficiente não permite que o progresso técnico de alguns setores produza efeitos de transbordamentos (spillovers) de forma homogênea para todos os demais setores da economia de determinado país. De acordo com Infante (2011) e Gusso et al. (2011), a presença de $\mathrm{HE}$ remete aos desdobramentos e à persistência das profundas desigualdades econômicas e sociais que se observam nos países em desenvolvimento. Além disso, a persistência da HE coloca difículdades para o 
estabelecimento de um processo de desenvolvimento inclusivo ou um modelo de crescimento com convergência de produtividade entre os setores, em linha com as proposições pioneiras da CEPAL.

Logo, a HE é fruto das insuficientes possibilidades de gerar e difundir o progresso técnico devido às características da especialização produtiva. Assim, aqueles países que não captam esses novos paradigmas tecnológicos apresentarão persistência de HE, baixos salários e um crescimento restringido pelo balanço de pagamentos (CIMOLI et al., 2005).

Para o Brasil, vários trabalhos voltados à essa temática têm sido desenvolvidos no período recente.

Catela et al. (2015) buscaram discutir se a hipótese da HE se aplica ao caso do setor industrial brasileiro. Os autores concluíram que a distribuição da produtividade não se alterou significativamente ao longo do período de 2000 a 2008, o que houve foi uma tendência de concentração. Segundo esses autores, as forças que sustentam a $\mathrm{HE}$ são aquelas identificadas pela literatura schumpeteriana como os motores da polarização, dando origem a retornos crescentes e dependência de trajetória, que concentram a inovação e a aprendizagem nas empresas que avançam. Os dados também apontaram diferenças significativas nos níveis de produtividade e no crescimento da produtividade em setores com diferentes intensidades tecnológicas.

Em outro trabalho semelhante, Catela e Porcile (2013a) analisaram a distribuição das firmas entre diferentes estratos de produtividade dentro da indústria de transformação no período de 2000 a 2009, assim como a dinâmica de transição destas firmas dentro e entre estes estratos. Além disso, buscaram testar se a heterogeneidade produtiva é um fenômeno persistente no tempo. Em suas conclusões, os autores confirmaram a elevada e persistente heterogeneidade dentro da indústria de transformação brasileira. Os resultados ratificam a existência de forte heterogeneidade intersetorial e intrassetorial.

Ainda com referência ao caso brasileiro, Catela e Porcile (2013b) investigaram a dinâmica da produtividade do trabalho das diferentes divisões da indústria de transformação brasileira e os seus determinantes. Os autores verificaram que a produtividade da indústria permaneceu praticamente inalterada entre 2000 e 2008, o que significou queda no adensamento das cadeias produtivas brasileiras, implicando deterioração da balança comercial, dado que as importações de insumos e bens intermediários aumentaram. Além disso, a dinâmica da distribuição condicional de produtividade evidencia a persistência da dispersão entre as divisões na indústria, o que confirma a ampla heterogeneidade que persiste ao longo do período.

A questão da HE com referência ao porte das empresas é, direta ou indiretamente, tratado em vários estudos sobre o tema. Destacam-se, na sequência, aqueles trabalhos que trataram mais diretamente a heterogeneidade segundo o porte, como os de Souza e Mazzali (2008), Hidalgo e da Mata (2008) e Kupfer e Rocha (2005).

Souza e Mazzali (2008) buscaram reunir, a partir de uma amostra de pequenas empresas, um conjunto de elementos que permitisse mostrar que o segmento dessas empresas é, em seu interior, heterogêneo, seja pelo número de empregados, pelos produtos e processos e/ou pelas formas de sua inserção em diferentes mercados. Os autores procuraram evidenciar a heterogeneidade do segmento das pequenas empresas, tanto no tamanho relativo das empresas, quanto nas formas de inserção. Para eles, heterogeneidade nas formas de inserção significa diferentes necessidades no que tange à continuidade das pequenas empresas no mercado e diferenças na sua possível contribuição, seja pela absorção da mão de obra, seja para contribuir na competitividade do setor em que se inserem.

Estes autores chegaram a quatro diferentes trajetórias de inserção para o segmento dos pequenos negócios: disputa de espaço em mercados ainda pouco oligopolizados e com acentuada concorrência em preços; identificação e exploração de oportunidades em "nichos" de mercado; parte integrante de aglomerações setoriais de empresas, sem liderança explícita; e inserção em redes de relações, mais frequentemente de subcontratação, comandadas por grandes empresas. Dessa forma, fica evidente que é inadequado o tratamento das pequenas empresas como um bloco homogêneo.

O trabalho de Hidalgo e da Mata (2008) buscou mostrar as diferenças de produtividade para as firmas exportadoras e não-exportadoras da indústria de transformação no período entre 1997 e 2003. Com o intuito de analisar a produtividade das firmas na indústria de transformação brasileira, os autores 
compararam a função de distribuição cumulativa da produtividade total dos fatores e da produtividade do trabalho para quatro grupos diferentes de firmas: exportadoras, não-exportadoras, exportadoras entrando no mercado internacional e exportadoras saindo do mercado internacional. Encontraram maiores níveis de produtividade para as firmas exportadoras do que para as firmas não-exportadoras. Em relação ao porte das empresas exportadoras, verificou-se que o grupo das firmas de pequeno porte possuíam maior nível de produtividade do que as não-exportadoras.

Kupfer e Rocha (2005) também analisaram a evolução da produtividade da indústria brasileira e procuraram medir a heterogeneidade a partir da dispersão dos níveis de produtividade entre os distintos setores e dentro de cada setor, assim como suas causas. Os autores concluíram que a intensificação da heterogeneidade não é um fenômeno apenas intersetorial, mas que há também um forte componente intrassetorial, que está associado, pelo menos em parte, ao tamanho das empresas. $\mathrm{O}$ tamanho das empresas explica melhor a evolução da produtividade que o setor de atividade.

Segundo os autores, não houve no Brasil uma mudança estrutural intersetorial relevante ao longo dos anos, mas sim uma significativa mudança estrutural intrassetorial. Isso aconteceu durante um processo de transformação em que as empresas de maior produtividade foram as que mais evoluíram, enquanto as restantes, geralmente as de pequeno porte, encontraram maiores dificuldades para avançar. Estas assimetrias entre empresas de maior e menor tamanho podem apontar que a modernização da indústria brasileira se caracterizou por um marcado aumento da heterogeneidade estrutural, principalmente de caráter intrassetorial.

\section{Metodologia}

Para o desenvolvimento desse trabalho foram utilizados dados secundários obtidos da Pesquisa Industrial Anual Empresa (PIA/Empresa) e do Cadastro Central de Empresas (CEMPRE), por meio de uma tabulação especial.

A PIA/Empresa é realizada pelo IBGE e possui em sua amostra todas as empresas industriais com 30 ou mais pessoas ocupadas. As demais empresas, numericamente majoritárias e com reduzida participação no total da atividade econômica, são objeto de seleção amostral. É importante destacar que essa pesquisa não inclui o setor informal, uma vez que fazem parte da PIA apenas aquelas empresas que possuem registro no Cadastro Nacional de Pessoa Jurídica (CNPJ) (BRASIL, 2019a). O CEMPRE também é organizado pelo IBGE e trata-se de um acervo de dados sobre o universo das empresas, reunindo informações provenientes de diversas pesquisas do IBGE e registros administrativos da Secretária de Trabalho do Ministério da Economia, como a Relação Anual de Informações Sociais (RAIS) (BRASIL, 2019b).

Nessa tabulação especial da PIA/Empresa e do CEMPRE, os dados são apresentados por faixa de idade da empresa, por porte da firma e por setor de atividade da indústria de transformação, segundo a Classificação Nacional de Atividades Econômicas (CNAE 2.0) a dois dígitos, para o período de 2007 a 2016, no Brasil.

No presente trabalho considera-se que as micro e pequenas empresas são estabelecimentos com até 99 pessoas ocupadas, empresas de médio porte têm de 100 a 499 pessoas ocupadas e as grandes empresas empregam mais de 500 pessoas, seguindo a classificação adotada pelo Serviço Brasileiro de Apoio às Micro e Pequenas Empresas (SEBRAE). Já as faixas de idade das empresas foram assim definidas: firmas com menos de 10 anos, com 10 a 19 anos, entre 20 e 29 anos e aquelas com mais de 30 anos.

Considerando os apontamentos da seção anterior e as informações obtidas, a principal variável investigada no trabalho é a produtividade do trabalho, dada pela relação do Valor da Transformação Industrial (VTI) pelo pessoal ocupado (PO). Ressalta-se que os dados monetários foram atualizados para valores de 2016, utilizando o Índice Nacional de Preços ao Consumidor (INPC), elaborado e disponibilizado pelo IBGE.

Por fim, menciona-se que a metodologia adotada foi uma análise descritiva dos dados, investigando a manifestação de HE na indústria de transformação do Brasil, considerando o porte, setor e o tempo de existência das empresas. 


\section{Análise dos Resultados}

A heterogeneidade estrutural, conforme definida originariamente pela CEPAL, se manifesta sempre que houver grandes diferenças na produtividade do trabalho, seja entre os setores da economia, bem como no seu interior. Estas diferenças, quando significativas, são capazes de promover uma segmentação do sistema produtivo e do mercado de trabalho, apresentando estratos de remuneração e condições tecnológicas bastante distintas (CEPAL, 2010a, 2007, 2008; PINTO, 1965, 1970; SUNKEL, 1971).

A fim de adicionar novos elementos à essa discussão, considera-se os diferentes portes de empresas com o objetivo de verificar se se verificava as relações sugeridas pela literatura de referência, ou seja, a produtividade é crescente como o porte e o tempo de existência das empresas no mercado.

Nessa direção, o primeiro item analisado neste trabalho é a produtividade do trabalho para a indústria de transformação por um período de 10 anos, de 2007 a 2016 . Os gráficos 1 a 4 apresentam as diferenças de produtividade relativas ao porte e ao tempo de existência das empresas.

Verifica-se que as MPEs, independente do tempo de existência, apresentam baixa produtividade. Há um destaque para as micro empresas com mais de 30 anos, no ano de 2008. Este pode ser resultado do período de expansão econômica pelo qual passava o Brasil, acompanhado de políticas públicas voltadas para as MPEs, que envolviam o acesso ao crédito e outros instrumentos de apoio, estabelecidas em planos governamentais, como a Política Industrial, Tecnológica e de Comércio Exterior (PITCE).

Em contrapartida, para as grandes empresas (500 ou mais funcionários), observa-se a produtividade em mais de $\mathrm{R} \$ 135,00$ para todos os anos analisados, independente do tempo de existência. Destaca-se que os dados mostram que a maior taxa de produtividade para as empresas com mais de 30 anos se apresenta para todos os portes de empresas e para todos os anos, sendo quase sempre cerca de duas vezes a produtividade das empresas mais jovens, com menos de 10 anos de existência.

As diferenças de produtividade segundo o porte foram encontradas em diversos trabalhos, como em Kupfer e Rocha (2005). Para os autores, o tamanho das firmas é uma variável explicativa para as diferenças de produtividade e, portanto, da heterogeneidade estrutural da indústria brasileira.

Para Hidalgo e Da Mata (2008) as diferenças de produtividade são relacionadas à participação no comércio internacional, onde os níveis de competição são mais acirrados e mais altas as barreiras à entrada, o que favorece as grandes empresas e reforçam os diferenciais de produtividade.

Por sua vez, Lall (1994) relaciona a maior produtividade das grandes empresas aos processos de aprendizado. Como a acumulação do conhecimento se processa das categorias mais simples para as mais complexas, à medida que a empresa cresce e se torna mais madura apresenta melhores condições de know how e capabilities necessários para uma atuação mais eficiente.

De acordo com os dados dos gráficos, as empresas de médio porte (100 a 499 trabalhadores) apresentam produtividade na faixa intermediária, entre as de grande e pequeno porte. Entretanto, destaque-se que, tanto nesse segmento de empresas quanto no das micro (0 a 29) e das grandes empresas (mais de 500), não se verifica para todos os anos uma relação direta com o tempo de existência. Ou seja, encontram-se empresas mais jovens com maior produtividade que as mais longevas. Entende-se que esses dados evidenciam que a heterogeneidade estrutural é mais ampla e complexa do que se supõe quando se consideram apenas as diferenças de porte. 
Gráfico 1. Produtividade do trabalho - PO (0-29)

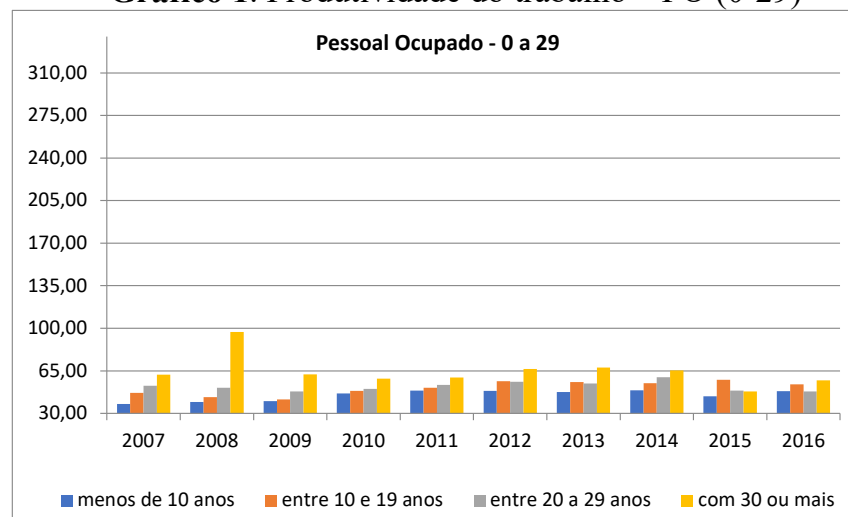

Fonte: Elaboração própria com base nos dados de Brasil (2018).

Gráfico 3. Produtividade do trabalho - PO (100-499)

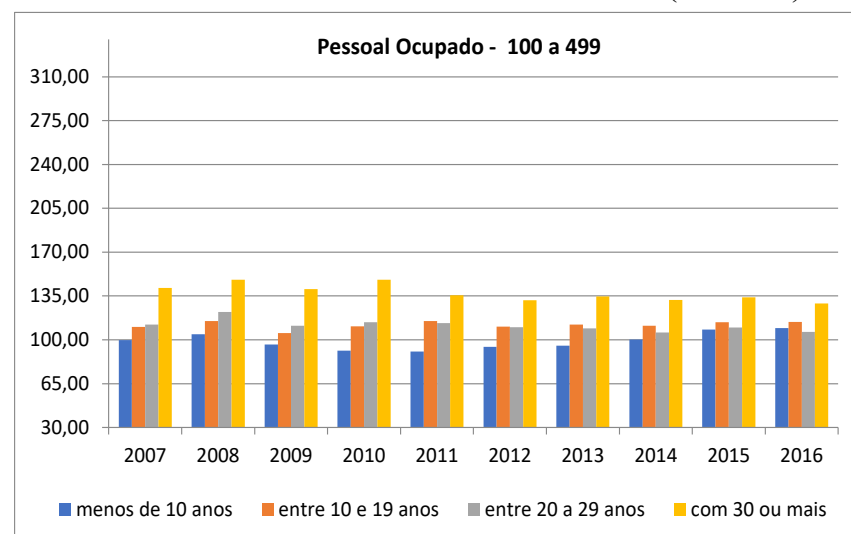

Fonte: Elaboração própria com base nos dados de Brasil (2018).
Gráfico 2. Produtividade do trabalho - PO (30-99)

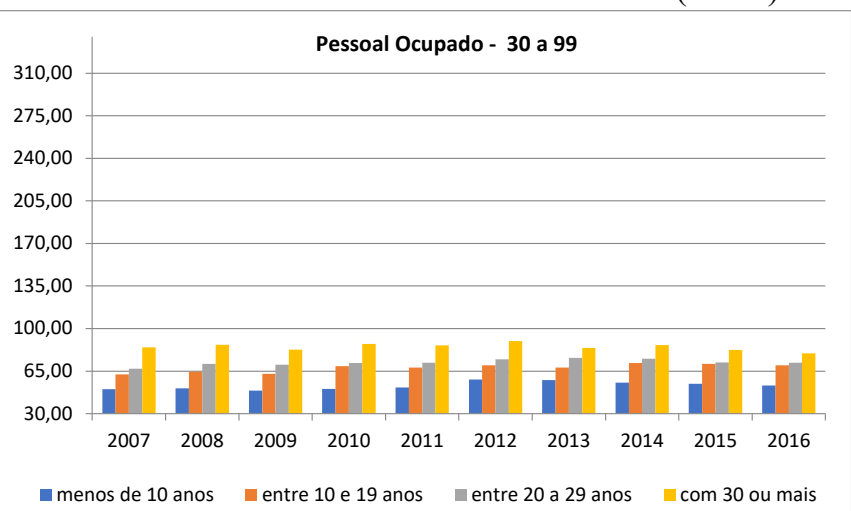

Fonte: Elaboração própria com base nos dados de Brasil (2018).

Gráfico 4. Produtividade do trabalho - PO (500 ou mais)

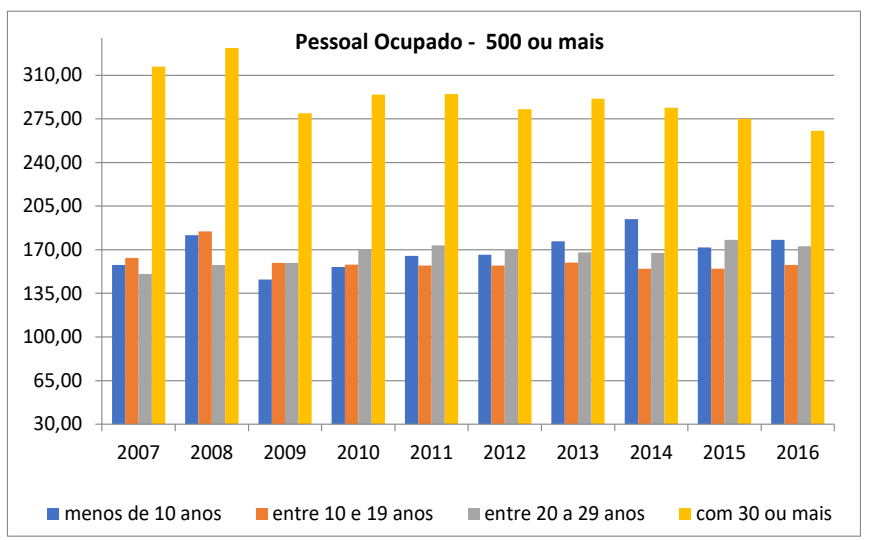

Fonte: Elaboração própria com base nos dados de Brasil (2018).

Analisando a produtividade ao longo do tempo, embora as empresas com mais tempo de existência (mais de 30 anos) tenham apresentado maior produtividade, independente do porte, a tabela 1 mostra que não houve crescimento de produtividade de 2007 para 2016. Ao contrário, a produtividade diminuiu. O valor mais expressivo foi encontrado para as empresas de grande porte com mais de 30 anos, que apresentou queda de $16 \%$ de 2007 para 2016.

Embora se verifique que a produtividade das grandes empresas tenha recuado de 2007 para 2016, os dados da tabela 1 mostram que houve um crescimento expressivo do VTI, bem como do emprego para esse mesmo período, para as grandes empresas com idade entre 10 e 19 anos e entre 20 e 29 anos. No entanto, para as empresas de grande porte com menos de 10 anos de idade, observa-se que tanto o VTI quanto o emprego diminuíram consideravelmente, sendo de $70 \%$ e $74 \%$ respectivamente.

Verifica-se, ainda, que todas as empresas consideradas jovens, até 10 anos, tiveram aumento de produtividade do ano de 2007 para o ano de 2016. Porém, pode-se inferir que é resultado da queda do VTI e do emprego em maior magnitude.

Alguns dados são relevantes de serem analisados, pois apontam para a não incorporação da tecnologia nos processos produtivos das firmas. A maioria dos casos, nos quais houve aumento do VTI, observou-se, também, aumento do emprego. Isto quer dizer, a heterogeneidade depende da velocidade relativa com que o progresso técnico é introduzido e difundido nas estruturas produtivas das firmas localizadas nos países em desenvolvimento como é o caso brasileiro (INFANTE, 2011). 
Tabela 1. Variação da produtividade, VTI e emprego do ano de 2007 para 2016

\begin{tabular}{|c|c|c|c|c|}
\hline $\begin{array}{c}\text { Faixa de Pess oal } \\
\text { Ocupado }\end{array}$ & $\begin{array}{l}\text { Tempo de } \\
\text { Exis tência }\end{array}$ & $\begin{array}{c}\text { Variação da } \\
\text { produtividade } \\
2007-2016\end{array}$ & $\begin{array}{c}\text { Variação do } \\
\text { VTI } \\
2007 \text { - } 2016\end{array}$ & $\begin{array}{c}\text { Variação do } \\
\text { emprego } \\
2007-2016\end{array}$ \\
\hline \multirow{4}{*}{ Com 0 a 29} & menos de 10 anos & $28 \%$ & $-19 \%$ & $-37 \%$ \\
\hline & entre 10 e 19 anos & $15 \%$ & $46 \%$ & $27 \%$ \\
\hline & entre 20 a 29 anos & $-9 \%$ & $64 \%$ & $80 \%$ \\
\hline & com 30 ou mais & $-8 \%$ & $52 \%$ & $65 \%$ \\
\hline \multirow{4}{*}{ Com 30 a 99} & menos de 10 anos & $6 \%$ & $-51 \%$ & $-53 \%$ \\
\hline & entre 10 e 19 anos & $12 \%$ & $24 \%$ & $11 \%$ \\
\hline & entre 20 a 29 anos & $7 \%$ & $56 \%$ & $45 \%$ \\
\hline & com 30 ou mais & $-6 \%$ & $28 \%$ & $35 \%$ \\
\hline \multirow{4}{*}{ com 100 a 499} & menos de 10 anos & $10 \%$ & $-61 \%$ & $-64 \%$ \\
\hline & entre 10 e 19 anos & $4 \%$ & $20 \%$ & $16 \%$ \\
\hline & entre 20 a 29 anos & $-5 \%$ & $27 \%$ & $34 \%$ \\
\hline & com 30 ou mais & $-9 \%$ & $2 \%$ & $12 \%$ \\
\hline \multirow{4}{*}{ com 500 ou mais } & menos de 10 anos & $13 \%$ & $-70 \%$ & $-74 \%$ \\
\hline & entre 10 e 19 anos & $-3 \%$ & $57 \%$ & $63 \%$ \\
\hline & entre 20 a 29 anos & $15 \%$ & $30 \%$ & $13 \%$ \\
\hline & com 30 ou mais & $-16 \%$ & $1 \%$ & $21 \%$ \\
\hline
\end{tabular}

Fonte: Elaboração própria com base nos dados de Brasil (2018).

Outra forma de se analisar a heterogeneidade é por setor. Neste trabalho foi realizado um esforço para comparar a produtividade por setor, por porte e por tempo de existência da firma nos anos de $2016 \mathrm{e}$ 2007. Foram separados os 24 setores de atividade da indústria de transformação, conforme CNAE 2.0. Para elaboração dos gráficos foram selecionados apenas os setores que apresentaram comportamento diferente do esperado, de acordo com a literatura.

Conforme os estudos sobre desenvolvimento e heterogeneidade estrutural, as firmas tendem a aumentar a produtividade à medida em que se tornam mais maduras. Isso significa que quanto mais tempo a firma permanece em atividade, maior será a sua produtividade (HIDALGO, DA MATA, 2008). Assim, os setores relacionados no quadro 1, são os que apresentaram comportamento padrão, de acordo com o prescrito na literatura. Verificou-se com os dados que à medida em que as empresas desses setores envelhecem, sua produtividade aumenta, independente do porte das empresas. Isso pôde ser observado tanto para 2016 quanto para 2007.

Quadro 1. Setores de atividade econômica com comportamento padrão.

\begin{tabular}{|l|l|}
\hline Fabricação de produtos de minerais não-metálicos & Fabricação de produtos alimentícios \\
\hline $\begin{array}{l}\text { Fabricação de máquinas, aparelhos e materiais } \\
\text { elétricos }\end{array}$ & Fabricação de produtos têxteis \\
\hline Fabricação de outros equipamentos de transporte & $\begin{array}{l}\text { Confecção de artigos do vestuário e } \\
\text { acessórios }\end{array}$ \\
\hline Fabricação de móveis & $\begin{array}{l}\text { Preparação de couros e fabricação de } \\
\text { artefatos }\end{array}$ \\
\hline Fabricação de produtos diversos & Impressão e reprodução de gravações \\
\hline $\begin{array}{l}\text { Manuntenção, repar. e inst. de máquinas e } \\
\text { equipamentos }\end{array}$ & $\begin{array}{l}\text { Fabricação de produtos de borracha e de } \\
\text { material plástico }\end{array}$ \\
\hline
\end{tabular}

Fonte: Elaboração própria com base nos dados de Brasil (2018).. 
No entanto, o mesmo não se pode afirmar sobre os demais setores, os quais apresentaram comportamento da produtividade bastante variado. A fim de identificar o comportamento desses setores, parte-se dos dados agregados setoriais, apresentados no gráfico 5 apresenta a produtividade das empresas por setor de atuação para os anos de 2007 e de 2016. A maior produtividade apresentada é referente ao setor de fabricação de produtos derivados do petróleo e biocombustível, com R\$1.216,00 em 2007 e $\mathrm{R} \$ 1.571,00$ em 2016. Exceto para o setor de farmoquímicos, todos os setores apresentaram aumento de produtividade do ano de 2007 para o de 2016.

Gráfico 5. Produtividade por setor para os anos de 2007 e 2016 (em R\$)

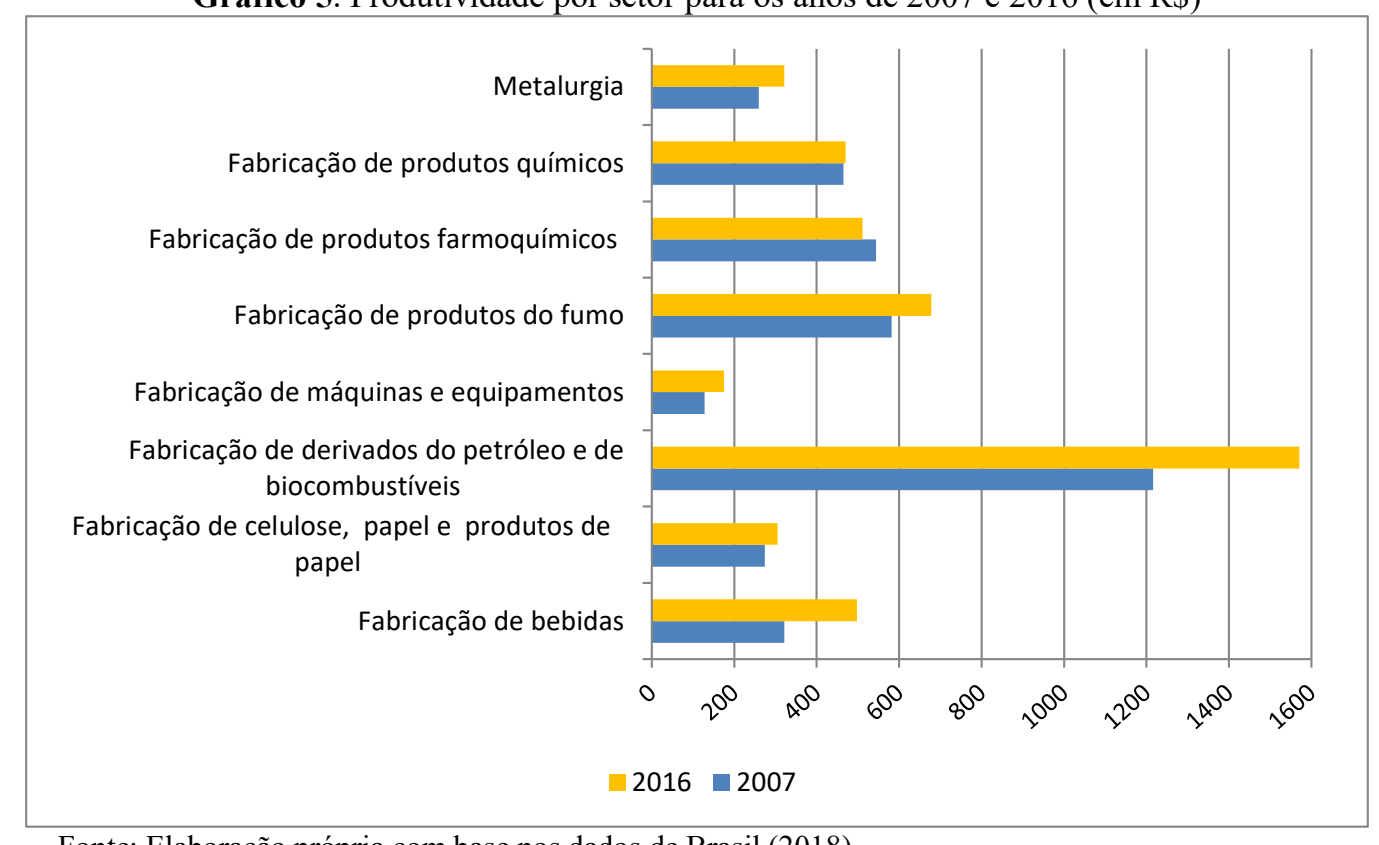

Fonte: Elaboração própria com base nos dados de Brasil (2018).

Conforme pode ser verificado nos gráficos seguintes, foi significativa a variação de produtividade quando se desagregam os dados por idade e faixa de tamanho.

Analisando a variação da produtividade de 2007 para 2016, para as empresas com idade entre $0 \mathrm{e}$ 9 anos, conforme gráfico 6, verifica-se que têm setores que aumentaram a produtividade nesse interim, embora, outros apresentem uma produtividade em 2016 menor que aquela evidenciada em 2007. A maior queda de produtividade foi para as empresas de grande porte observadas em 4 setores da economia, sendo o valor mais expressivo para o setor de metalurgia, com queda de mais de $75 \%$ na produtividade.

Vale ressaltar o expressivo aumento de produtividade das MPEs, com destaque para os setores de fabricação de bebidas, de fabricação de produtos de fumo e de fabricação de produtos farmoquímicos, que aumentaram a produtividade em $219 \%, 216 \%$ e $209 \%$, respectivamente. Embora os dados revelem que em 2016 o setor de fabricação de produtos químicos apresentou alta taxa de produtividade, verifica-se que de 2007 para 2016, houve queda da produtividade nesse setor, exceto para as micro empresas. 
Gráfico 5. Variação da Produtividade de 2007 para 2016 por setor, para empresas com 0 a 9 anos de existência

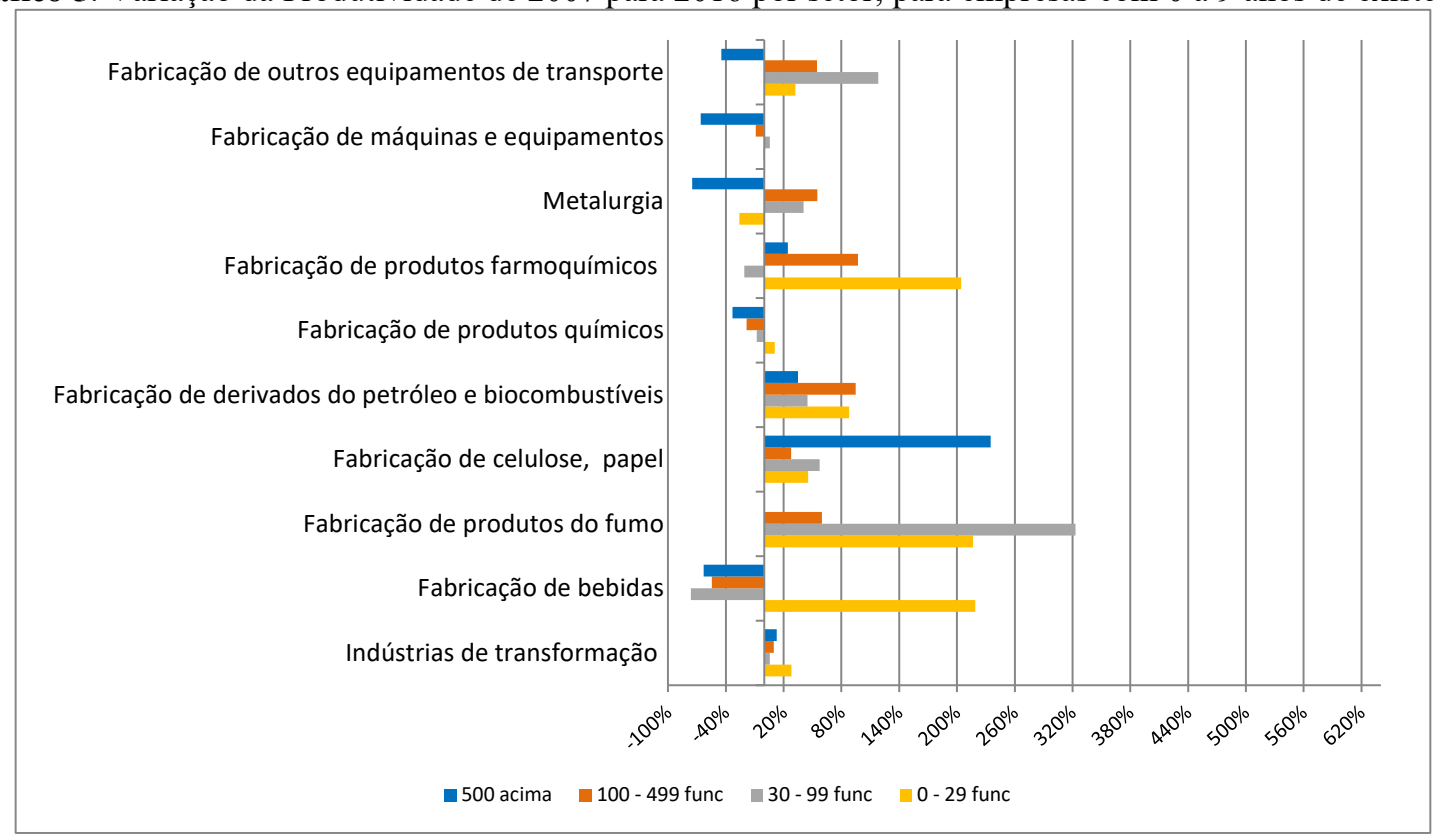

Fonte: Elaboração própria com base nos dados de Brasil (2018).

O gráfico 6 apresenta a variação da produtividade de 2007 para 2016, por setor, para as empresas com idade entre 10 e 19 anos. O setor de fabricação de derivados de petróleo e biocombustível se destaca em dois sentidos. Para as empresas de grande porte ele apresenta a maior taxa de crescimento da produtividade nesse período, alcançando o percentual de 891. No entanto, para MPEs observa-se uma queda na produtividade. Em 2007, esse setor, considerando as empresas de pequeno porte (30 a 99 funcionários) apresentou a maior produtividade dentre todos os setores da economia, chegando ao patamar de $\mathrm{R} \$ 715,00$, porém, não se mantém ao longo do tempo. Uma das explicações para essa alta produtividade no setor de fabricação de derivados de petróleo e biocombustível foi a descoberta do présal em águas brasileiras ${ }^{2}$.

Evidencia-se ainda, que a MPEs apresentam aumento de produtividade, mesmo que não seja na mesma proporção das empresas mais jovens, como apresentado no gráfico 5.

Destaque-se também que houve aumentos de produtividade maiores para as empresas de pequeno porte ( 0 a 29 empregados) no setor de fabricação de outros equipamentos de transporte e no setor de bebidas são as duas faixas de menor tamanho (0 a 99 empregados) as maiores responsáveis pelos aumentos de produtividade.

${ }^{2}$ Segundo a Agência Nacional do Petróleo, Gás Natural e Biocombústivel (ANP), a produtividade dos poços do pré sal é alta. A produção diária de petróleo no pré sal passou da média de aproximadamente 41 mil barris por dia, em 2010 , para o patamar de 1,35 milhão de barris por dia em junho de 2017. Um crescimento de mais de 3mil\%. Nesse mesmo mês, a produção de petróleo no pré sal superou a do pós sal, que totalizou 1,32 milhão de barris por dia. as mudanças na produção do biocombustível, também cooperaram para o resultado final da produtividade do setor. Segundo o Ministério da Agricultura, houve aumento na produção de biocombustível de mais de $200 \%$. 
Gráfico 6. Variação da Produtividade de 2007 para 2016 por setor, para empresas com 10 a 19 anos de existência

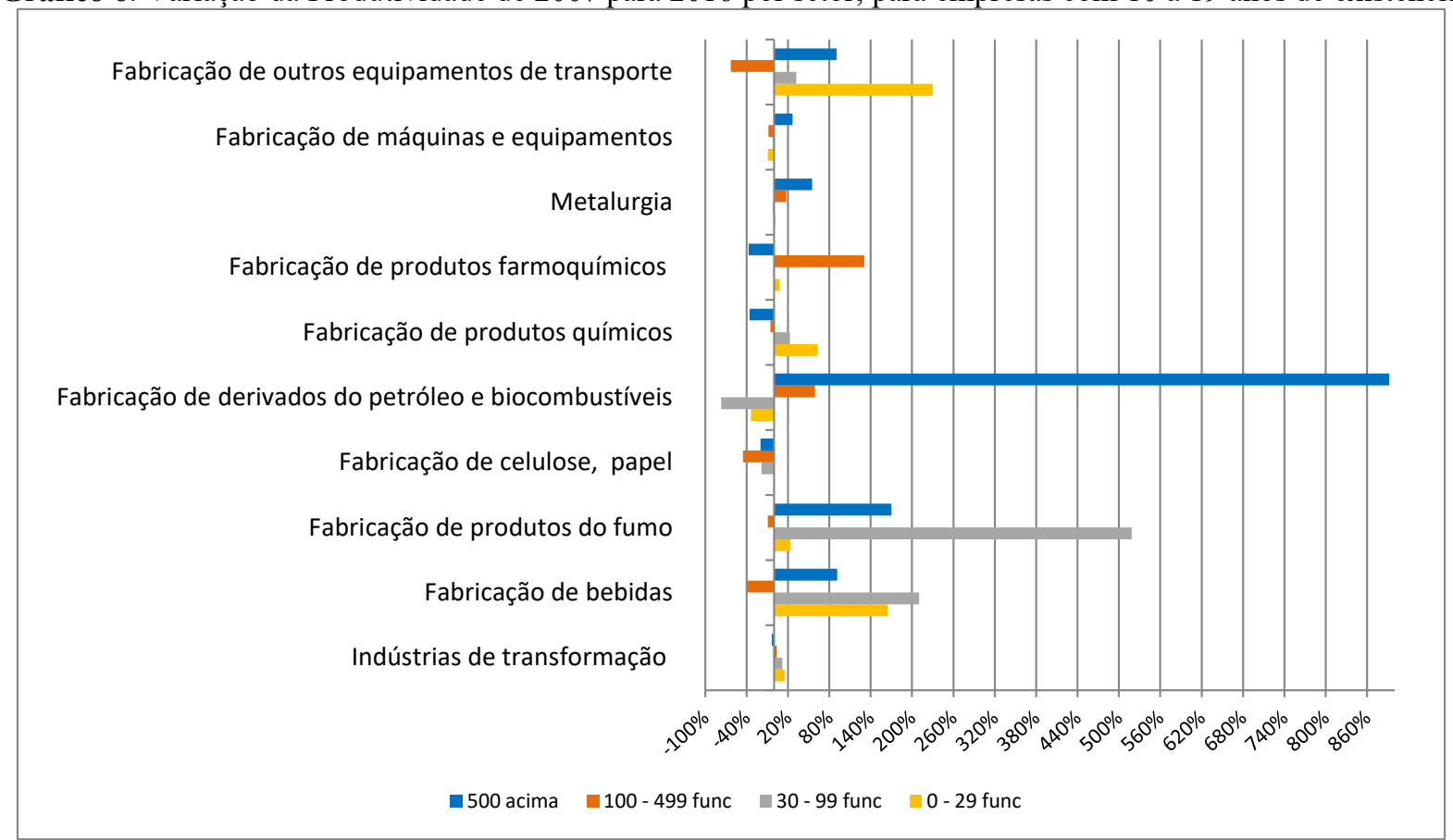

Fonte: Elaboração própria com base nos dados da PIA

Para as empresas com idade entre 20 e 29 anos de atuação, o comportamento da taxa de variação da produtividade de 2007 para 2016 é ainda mais distinto que os demais, conforme gráfico 7. Destaque para o setor de fabricação de produtos do fumo, para as empresas de médio porte. O que não se observou para esse mesmo setor com mesmo porte, porém com idades diferentes. Para as empresas entre 10 e 19 anos, desse setor, houve queda de produtividade de 2007 para 2016. Para as empresas mais jovens, com menos de 10 anos, observou-se um aumento de quase $80 \%$, o que fica bem distante do aumento evidenciado aqui (gráfico 7 ) de quase $580 \%$.

Em 2007 a produtividade do setor de metalurgia se aproximava de R\$570,00, mas em 2016 esse valor foi de apenas $\mathrm{R} \$ 152,00$, o que aponta para uma queda de produtividade de quase $80 \%{ }^{3}$.

Cabe citar também que nessa faixa de idade nos setores de outros equipamentos de transporte, produtos farmoquímicos e bebidas são as empresas menores ( 0 a 29 trabalhadores) que obtiveram os maiores ganhos de produtividade.

3 O Instituto Aço Brasil, em 2017 divulgou uma nota, na qual afirma que uma das razões para a queda de produtividade do setor são as mudanças na concorrência externa. Segundo o Instituto, um dos pontos significativos do atual momento é o excesso de capacidade global de produção, que hoje ultrapassa 545 milhões de toneladas (280 milhões somente na China). Outro fator refere-se aos subsídios dados pela China à sua produção, o que também impactou na produtividade do setor no Brasil. De acordo com o Instituto do Aço, a sobretaxa de $25 \%$ para o aço importado, de alguns países, incluindo o Brasil, contribuiu de forma negativa na taxa de produtividade do setor. 
Gráfico 7. Variação da Produtividade de 2007 para 2016 por setor, para empresas com 20 a 29 anos de existência.

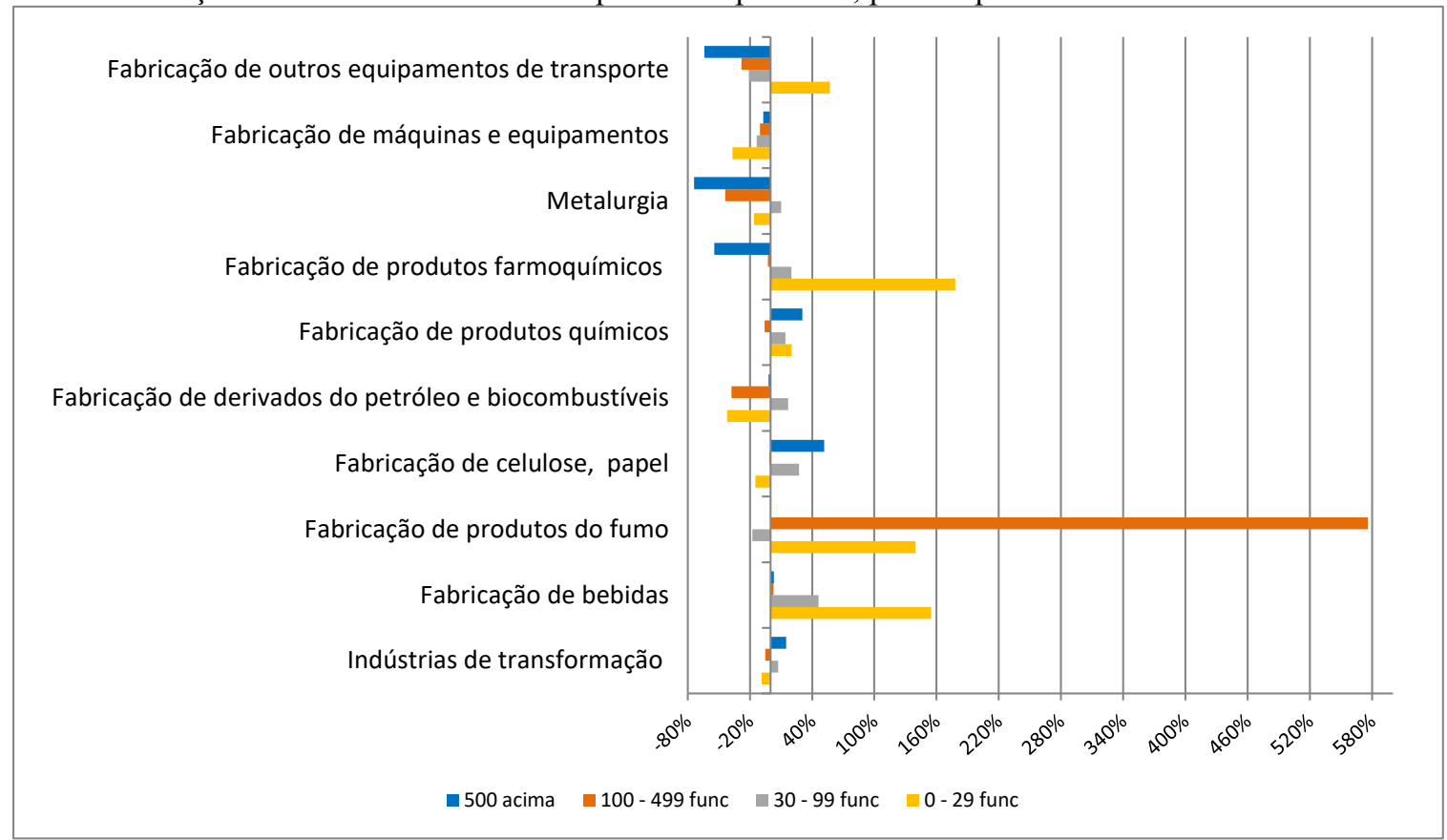

Fonte: Elaboração própria com base nos dados de Brasil (2018).

O gráfico 8 mostra a variação de produtividade de 2007 para 2016, das empresas com mais de 30 anos de atuação. Verifica-se que foram as empresas que mais apresentaram queda de produtividade no período. Embora os dados apontem as empresas de grande porte do setor de fabricação de derivados de petróleo e biocombustível como as de maior produtividade, sendo de mais de R \$1.460,00 em $2007 \mathrm{e}$ $\mathrm{R} \$ 1.558,00$ em 2016, apenas as micro empresas do setor apresentaram aumento significativo de produtividade de 2007 para 2016 , de quase $600 \%$.

Gráfico 8. Variação da Produtividade de 2007 para 2016 por setor, para empresas com 30 anos ou mais de existência

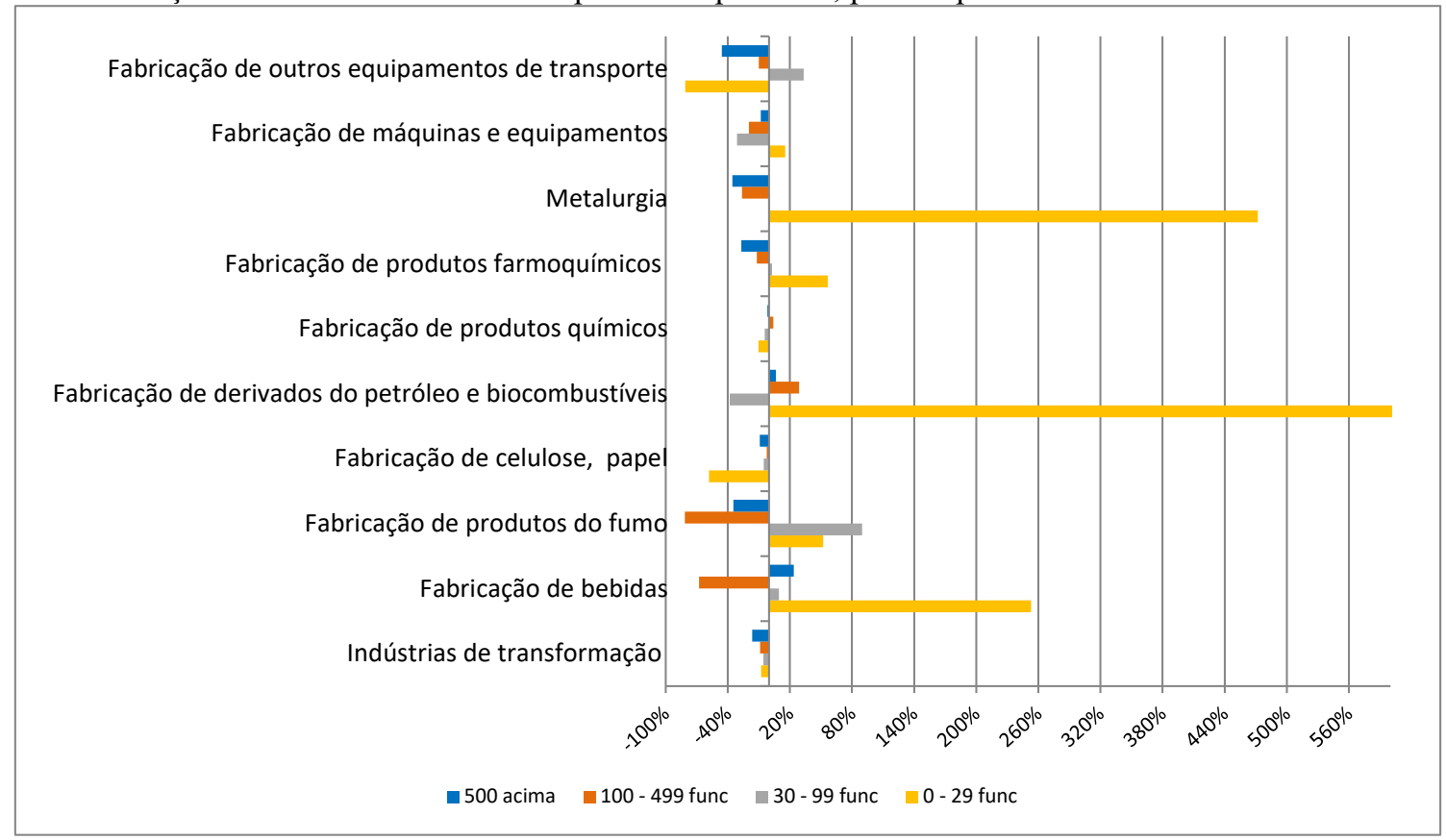

Fonte: Elaboração própria com base nos dados de Brasil (2018).

Os dados apresentados mostram que, no geral, as empresas jovens foram as que mais sofreram impactos das mudanças na economia. A análise da variação da produtividade de 2007 para 2016, seja do valor total para a indústria de transformação, seja setorial, apontam que a economia brasileira sofreu com os reflexos da crise de 2008. 
Segundo Hidalgo e Da Mata (2008), as variáveis estruturais não são capazes de explicar completamente a baixa produtividade brasileira. Faz-se necessário, assim, analisar fatores sistêmicos, com abordagem mais microeconômica. Pois, entende-se que a produtividade, apesar de ser influenciada "por fatores exógenos, é um atributo da firma e resultado, em última instância, de suas decisões econômicas. Nesse sentido, existem também diferenciais de produtividade e de desempenho econômico entre as empresas dentro de um mesmo setor de atividade" (DE NEGRI, CAVALCANTE, 2014:45).

A análise setorial deixa ainda mais evidente a heterogeneidade estrutural. Foi possível observar que, contrariamente ao postulado pela literatura, parte importante dos setores da indústria brasileira não apresentam ganhos de know how à medida em que as empresas envelhecem, ganhos esses que podem proporcionar aumentos de produtividade. Embora com dados agregados não seja possível fazer uma correlação estatística para demonstrar essa afirmação, verifica-se que, mesmo se considerarmos que uma empresa cresceu, mudou a faixa de porte ou aumentou seu tempo de existência, não se verifica que há, de forma correlata, aumento de produtividade. Ao contrário, observou-se, em vários setores, que independentemente do tamanho e da idade das empresas, não houve sequência de crescimento da taxa de produtividade.

Com base na abordagem de Pinto (1970), pode-se dizer que a estrutura primitiva e a estrutura moderna, em termos de produtividade, no caso brasileiro, se alternam. Ora as grandes empresas mais velhas apresentam-se como a estrutura moderna, ora as micro empresas mais jovens apresentam as maiores taxas de produtividade e podem se caracterizar como sendo as modernas.

\section{Considerações Finais}

Os debates sobre a heterogeneidade estrutural da economia brasileira, até pouco tempo atrás, eram restritos a uma linha de pesquisa, que buscava investigar os determinantes do Desenvolvimento Econômico. No entanto, outras áreas no ambiente acadêmico, principalmente no âmbito da Microeconomia e Economia Industrial, têm-se voltado para o tema, com o intuito de investigar os fatores determinantes da produtividade e as causas da heterogeneidade. Esse debate foi ampliado nos últimos anos com as evidências do processo de desindustrialização da economia brasileira.

As análises de manifestação de heterogeneidade dependem da metodologia de cálculo utilizada para esse fim. Os indicadores usualmente adotados são: produtividade, comumente usada como a produtividade do trabalho; densidade industrial, market share e estrutura de salários. Para este trabalho, utilizou-se a produtividade do trabalho, com o intuito de evidenciar a heterogeneidade estrutural (HE) relativa ao porte e ao tempo de existência das empresas na indústria de transformação brasileira de 2007 a 2016.

Para isso, foram estabelecidos duas linhas de análises: (i) apresentar as diferenças de produtividade ao longo do tempo por porte e por idade; (ii) apresentar a diferença setorial por porte e por idade em dois pontos do tempo, quais sejam 2007 e 2016.

Verificou-se que, para a indústria de transformação como um todo, as empresas de grande porte, com mais de 500 funcionários são as que apresentam as maiores taxas de produtividade, embora também tenham sofrido redução da produtividade de 2007 para 2016.

No que tange às diferenças ao longo do tempo, por porte e por idade das empresas, observou-se que não se apresenta uma linha crescente de produtividade. Não foi possível identificar que à medida que as empresas envelhecem, aumentam a produtividade, como era o resultado esperado. Ao contrário, observou-se que as empresas maiores (mais de 500 funcionários) e mais antigas (mais de 30 anos de existência) foram as que apresentaram a maior queda de produtividade de 2007 para 2016 e que as empresas jovens e de menor porte sobressaíram-se com as maiores taxas de aumento de produtividade.

Quanto às diferenças setoriais, por porte e por idade, também constatou-se grande heterogeneidade. Não apenas na comparação de um setor com outro, mas dentro do próprio setor, ao se analisar a idade e o tamanho das empresas, verificou-se a existência de significativos diferenciais de produtividade.

Entende-se que o conjunto de dados apresentados contribui para o avanço do conhecimento sobre a heterogeneidade estrutural que caracteriza a indústria brasileira e à análise do processo de 
desindustrializaçao, ao sistematizar a comparação entre os diferentes portes e, em especial, por agregar informações de tempo de existência das empresas, variável que não foi analisada em nenhum dos trabalhos sobre o tema, até onde é de conhecimento das autoras.

Os resultados encontrados permitem mostrar, em suma, que não há uma separação simples entre pequenas empresas de baixa produtividade e grandes empresas de alta produtividade. Tampouco é possível atribuir às empresas mais longevas as mais altas taxas de produtividade, dado que encontrou-se significativas diferenças intersetoriais quando cruzados os dados de tempo de existência e setor de atividade.

Portanto, esses achados corroboram e agregam novas informações a outros estudos recentes que comprovaram a existência de HE no setor industrial brasileiro. Em termos de desenvolvimento futuro dessa linha de investigação, uma análise mais detalhada, observando os microdados para as empresas, por porte, por setor e tempo de existência, poderá contribuir de forma mais precisa para identificar a manifestação de heterogeneidade e, principalmente, apontar os seus determinantes, em nível micro ou macroeconômico.

\section{Referências}

ARAÚJO, Eduardo Santos; COSTA, Kaio Glauber Vidal da. Heterogeneidade estrutural, precarização das condições de trabalho e pleno emprego no ciclo de desenvolvimento da economia brasileira entre 2002-2011. Revista Economia \& Tecnologia, Curitiba, v. 8, n. 3, p. 5-18, 2012. ISSN 2238-1988.

CATELA, Eva Yamila; CIMOLI, Mario; PORCILE, Gabriel. Productivity and Structural Heterogeneity in the Brazilian Manufacturing Sector: Trends and Determinants. Oxford Development Studies, v. 43, n. 2, p. 232-252. 2015.

CATELA, Eva Yamila da Silva; PORCILE, Gabriel. Heterogeneidade estrutural na produtividade das firmas brasileiras. Brasília: CEPAL. Escritório no Brasil/IPEA. Textos para Discussão CEPAL-IPEA, 55. 2013a. 38 p.

CATELA, Eva Yamila da Silva; PORCILE, Gabriel. Produtividade setorial da indústria brasileira: uma análise dos determinantes a partir de regressão quantílica para painel de dados com efeitos fixos. In: $\mathbf{4 6}^{\mathbf{0}}$ Encontro Nacional de Economia - ANPEC 2013, Foz do Iguaçu. Anais [...], 2013b.

CIMOLI, Mario. Heterogeneidad estructural, asimetrías tecnológicas y crecimiento en América Latina. Santiago: CEPAL, 2005.

De NEGRI, F.; CAVALCANTE, L. R. Os Dilemas E Os Desafios Da Produtividade No Brasil.

IN: Produtividade no Brasil : desempenho e determinantes / organizadores: Fernanda De Negri, Luiz Ricardo Cavalcante. - Brasília : ABDI : IPEA, 2014.

GUSSO, Divonzir Arthur; NOGUEIRA, Mauro Oddo; VASCONCELOS, Lucas Ferraz. Heterogeneidade Estrutural: uma retomada conceitual. Boletim Radar - Tecnologia, Produção e Comércio Exterior, $n$. 14, Brasília: Ipea, 2011.

HIDALGO, Álvaro Barrantes; DA MATA, Daniel. Produtividade e Desempenho Exportador das Firmas na Indústria de Transformação Brasileira. In: 36 Encontro Nacional de Economia - ANPEC 2008,

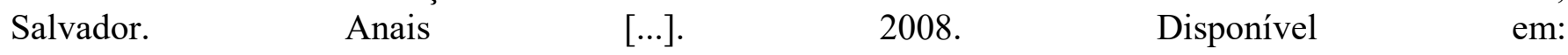
http://www.anpec.org.br/encontro2008/artigos/200807121045090-.pdf. Acesso em: 18 fev. 2019. 
INFANTE, Ricardo (Ed.). El desarrollo inclusivo en América Latina y el Caribe: Ensayos sobre políticas de convergencia productiva para la igualdad. Santiago: Publicación de las Naciones Unidas, 2011. ISBN: 978-92-1-121781-0.

KUPFER, David; ROCHA, Frederico. Productividad y heterogeneidad estructural en la industria brasileña. In: CIMOLI, Mario (Ed.). Heterogeneidad estructural, asimetrías tecnológicas y crecimiento en América Latina. Santiago: CEPAL, 2005.

LALL, S. Technological capabilities and industrialization. World Development, v. 20, n. 2, p.165- 86, 1992.

LEWIS, William Arthur. Economic development with unlimited supplies of labour. The Manchester School, May 1954.

NOGUEIRA, Mauro Oddo. Um pirilampo no porão: um pouco de luz nos dilemas da produtividade das pequenas empresas e da informalidade no Brasil. Brasília: Ipea, 2017. 308 p.

PINTO, Aníbal. Naturaleza e implicaciones de la 'heterogeneidad estructural' de la América Latina. El trimestre económico, vol. 37(1), n. 145, México, D.F., Fondo de Cultura Económica, enero-marzo, 1970. Disponível em: https://www.cepal.org/es/publicaciones/2037-cinquenta-anos-pensamento-cepal. Acesso em: 05 jan. 2019.

SOLOW, Robert Merton. A contribution to the theory of economic growth. The Quarterly Journal of Economics, The MIT Press, v. 70, n. 1, p. 65-94, Feb. 1956. Disponível em: <http://www. jstor.org/stable/1884513>.

SOUZA, Maria Carolina de Azevedo Ferreira de. Pequenas e Médias empresas na reestruturação industrial. Brasília: SEBRAE, 1995.

SOUZA, Maria Carolina de Azevedo Ferreira de; MAZZALI, Leonel. Conceito e espaço da pequena empresa na estrutura industrial: heterogeneidade e formas de inserção. Revista Gestão \& Produção, São Carlos, v. 15, n. 3, p. 591-603, 2008. 